\title{
Multiple Subclasses of Purkinje Cells in the Primate Floccular Complex Provide Similar Signals to Guide Learning in the Vestibulo-Ocular Reflex
}

\author{
Jennifer L. Raymond ${ }^{1}$ and Stephen G. Lisberger \\ Department of Physiology \\ and W.M. Keck Foundation Center for Integrative Neuroscience \\ University of California \\ San Francisco, California 94143
}

\begin{abstract}
The neural "learning rules" governing the induction of plasticity in the cerebellum were analyzed by recording the patterns of neural activity in awake, behaving animals during stimuli that induce a form of cerebellum-dependent learning. We recorded the simple- and complex-spike responses of a broad sample of Purkinje cells in the floccular complex during a number of stimulus conditions that induce motor learning in the vestibulo-ocular reflex (VOR). Each subclass of Purkinje cells carried essentially the same information about required changes in the gain of the VOR. The correlation of simple-spike activity in Purkinje cells with activity in vestibular pathways could guide learning during low-frequency but not high-frequency stimuli. Climbing fiber activity could guide learning during all stimuli tested but only if compared with the activity present $\sim 100$ msec earlier in either vestibular pathways or Purkinje cells.
\end{abstract}

\section{Introduction}

How are the sensory signals that guide learning converted into appropriate cellular or synaptic changes in the brain? The cerebellum provides an opportunity to examine this question because cellular mechanisms of plasticity in the cerebellum are under intense scrutiny and likely sites of plasticity have been identified for several behaviors that exhibit cerebellum-dependent learning. Nevertheless, cellular analyses of plasticity and sys-

\footnotetext{
${ }^{1}$ Corresponding author.
}

tems-level analyses of cerebellum-dependent learning have met at an uneasy boundary, because cellular studies have used electrical or chemical stimulation protocols that are difficult to relate to the more natural situations encountered during learning. Our goal was to bridge the gap between cellular analyses of plasticity in the cerebellum and systems analyses of learning by documenting the neural signals available to drive the induction of plasticity during cerebellum-dependent learning in vivo. Our approach was to record the signals present in multiple subclasses of Purkinje cells during motor learning in the vestibulo-ocular reflex (VOR). These recordings reveal the neural environment in which mechanisms of plasticity must function during learning in intact animals.

The VOR exhibits many similarities with other forms of cerebellum-dependent learning (Raymond et al. 1996) and provides a tractable system in which to study issues such as the role of specific forms of plasticity in cerebellar function. The VOR uses vestibular inputs to drive compensatory eye movements in the opposite direction from head turns, thereby stabilizing the eyes in space and minimizing image motion across the retina during head movement. Motor learning calibrates the VOR by modifying the reflex whenever retinal image motion is associated with head turns (Gonshor and Melvill Jones 1973; Ito et al. 1974; Miles and Fuller 1974; Gauthier and Robinson 1975). Normally, the gain of the VOR (defined as the ratio of eye speed to head speed in the absence of visual input) is close to 1.0. If head turns are accompanied by image motion in the same direction as the head turn, then the gain of the VOR is too large and a learned decrease is induced in the gain of the VOR. If head turns are accompanied by image motion in the opposite direction from the head turn,

LEARNING \& MEMORY 3:503-518 @ 1997 by Cold Spring Harbor Laboratory Press ISSN1072-0502/97 \$5.00

$$
\begin{array}{lllllllllllllllll}
\mathcal{Q} & E & A & R & N & I & N & G & M & E & M & O & R & Y \\
503 & & & & & &
\end{array}
$$


then the gain of the VOR is too small and a learned increase is induced in the gain of the VOR. Thus, learning is guided by the directional relationship between image motion and head turns, which are signaled to the brain by visual and vestibular sensory inputs.

Previous work has identified two sites of plasticity associated with learning in the VOR (Fig. 1) (Dufosse et al. 1978; Miles et al. 1980b; Watanabe 1984; Lisberger and Pavelko 1988; Lisberger 1994; Lisberger et al. 1994b,c; Luebke and Robinson 1994; Pastor et al. 1994; Partsalis et al. 1995). One site is in the vestibular pathway to Purkinje cells in the floccular complex (flocculus and ventral paraflocculus) of the cerebellar cortex. The other site is in the vestibular inputs to neurons in the vestibular nucleus that are targets of inhibition from the floccular complex [floccular target neurons (FTNs)]. With putative sites of memory identified, an important next step is to determine how the association of vestibular and visual inputs triggers the induction of appropriate neural changes at these sites of plasticity in the circuit for the VOR. Plasticity at either site could be controlled by three neural signals that are present at both sites: (1) the activity of vestibular inputs (vestibular parallel fibers or brainstem vestibular pathways), (2) the activity of climbing fibers carrying visual signals, and (3) the simple-spike activity of Purkinje cells, which carry a combination of vestibular, visual, and eye movement signals. We have evaluated combinations of these three signals to determine whether their comparison provides information about whether to increase or decrease the gain of the VOR. Pat-

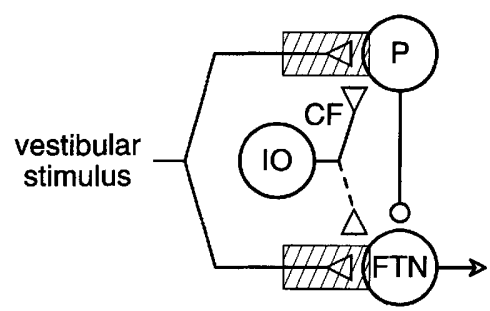

Figure 1: Simplified circuit diagram for the VOR. The putative sites of plasticity are indicated by the shaded regions. Three neural signals converge at each site: the activity of inputs driven by the vestibular stimulus, the activity of climbing fibers (CFs) from the inferior olive $(\mathrm{IO})$, and the simple-spike activity of Purkinje cells (P). (FTN) Flocculus target neuron in the vestibular nucleus. The dashed climbing fiber collateral to the FTN indicates that this connection may exist but is not well described (Balaban et al. 1981). terns of activity that were consistently present during stimuli that cause a decrease in the gain of the VOR but were not present during stimuli that cause an increase in gain or vice versa would be candidates for the neural "error" signals that guide learning.

Purkinje cells in the floccular complex of the rhesus monkey have been divided into classes on the basis of their responses during eye movements with the head stationary and during vestibular stimulation. Many studies of the contribution of the floccular complex to the VOR have focused on a subclass of Purkinje cells, called horizontal gaze velocity Purkinje cells (HGVPs), which respond with an increase in firing rate to ipsiversive eye movement and to ipsiversive vestibular stimulation. Several lines of evidence suggest that the HGVPs play an important role in learning: Lesions of the floccular complex disrupt learning in the VOR (Ito et al. 1974; Robinson 1976; Nagao 1983; Lisberger et al. 1984; Barmack and Pettorossi 1985; Luebke and Robinson 1994; Pastor et al. 1994; Partsalis et al. 1995), the responses of HGVPs during the VOR are modified after learning (Miles et al. 1980b; Watanabe 1984; Lisberger et al. 1994c), and computational analyses indicate that changes in the vestibular inputs to HGVPs are required to account for the changes in HGVP firing associated with learning (Lisberger and Sejnowski 1992; Lisberger 1994). In a previous study (Raymond and Lisberger 1996b; J.L. Raymond and S.G. Lisberger, unpubl.), we evaluated the possible ways that the HGVPs and their inputs could guide the induction of learning and found that (1) the correlation of simple-spike activity in the HGVPs with the vestibular stimulus could guide learning during lowbut not high-frequency sinusoidal visual/vestibular stimuli; (2) the correlation of simple spike activity in HGVPs with activity in their climbing fiber inputs could guide learning during high- but not lowfrequency stimuli; and (3) the correlation between the climbing fiber and vestibular inputs to HGVPs could guide learning at all stimulus frequencies if plasticity were regulated by the comparison of a climbing fiber input with the vestibular inputs that were present $\sim 100$ msec earlier.

Our goal in the present study was to evaluate the possible contributions to learning of Purkinje cells in the floccular complex that are not HGVPs. Some of these Purkinje cells modulate their firing rate solely in relation to eye movements (eye-movement-only Purkinje cells), and others modulate in relation to head movements but cannot be classi-

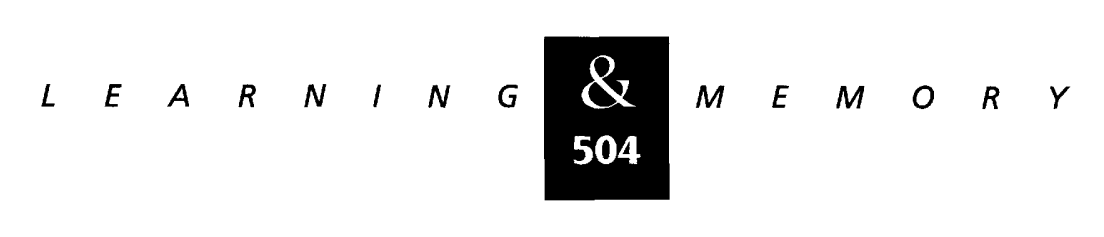


fied as HGVPs. As Nagao (1992) has pointed out, these other subclasses of Purkinje cells could play an important role in the VOR. Therefore, we evaluate whether the discharge of these subclasses of cells during the induction of motor learning in the VOR suggests a role that is fundamentally different from that of the HGVPs. Our analysis reveals that the signals present in the non-HGVP Purkinje cells in the floccular complex have about the same capacity for guiding learning as the signals present in the HGVPs.

\section{Materials and Methods}

Experiments were conducted on two male rhesus monkeys that had been trained to perform a visual fixation task (after Wurtz 1969) to obtain liquid reinforcement. Using methods that have been described previously, monkeys were anesthetized with isofluorane and sterile procedure was used to implant bolts in the skull for restraining the head (Lisberger and Westbrook 1985) and to implant a coil of wire on one eye for measuring horizontal and vertical eye position (Judge et al. 1980). In a second surgical procedure, a recording cylinder was cemented over a hole in the calvarium to allow access to the cerebellum for single unit recording. The cylinder was placed stereotaxically at an angle of $26^{\circ}$ (electrodes running in the sagittal plane from back to front) and aimed at the anterior-posterior location of the ear bars, $11 \mathrm{~mm}$ lateral to the midline (Lisberger et al. 1994c).

During experiments, each monkey sat in a specially designed primate chair, to which his implanted head holder was secured. Platinum-iridium electrodes were used to make recordings from Purkinje cells in the floccular complex of the cerebellum (flocculus and ventral paraflocculus) while the monkey viewed moving visual stimuli and underwent passive whole body rotation about a vertical axis. Vestibular stimuli were provided by a servocontrolled turntable (Contraves-Goertz, model 813) that rotated the monkey, the chair, and a set of 18-inch magnetic field coils together about a vertical axis.

After a Purkinje cell was isolated, it was first characterized by its responses during two tracking conditions that have been used previously to categorize neurons in the circuit for the VOR: (1) during the smooth pursuit eye movements evoked by sinusoidal motion of a small spot along the horizontal axis at $0.5 \mathrm{~Hz}, \pm 31.4^{\circ} / \mathrm{sec}$; and (2) as the monkey canceled his VOR by tracking a spot that moved exactly with sinusoidal head rotation at $0.5 \mathrm{~Hz}, \pm 31.4^{\circ} / \mathrm{sec}$. Almost all of the Purkinje cells also were tested during pursuit of target motion along the vertical axis at $0.5 \mathrm{~Hz}, \pm 31.4^{\circ} / \mathrm{sec}$. For these initial behavioral conditions, the visual stimulus was a small spot subtending $0.5^{\circ}$ of visual angle.

After initial characterization recordings were made from the Purkinje cell under conditions that cause learning in the VOR. Sinusoidal head rotation was paired with the motion of a high contrast, black and white pattern that was reflected off a mirror galvanometer onto the back of a tangent screen $114 \mathrm{~cm}$ in front of the eyes. The visual stimulus subtended $30^{\circ}$ along the horizontal meridian and $20^{\circ}$ along the vertical meridian. The vestibular stimulus was sinusoidal head motion at a single frequency between $0.2 \mathrm{~Hz}$ and $10 \mathrm{~Hz}$ and with a peak-to-peak velocity of $20^{\circ} / \mathrm{sec}$, unless otherwise noted. The visual stimulus moved either exactly with or exactly opposite to the head motion, thereby creating stimulus conditions for which the optimal tracking eye velocity was either zero times or two times the eye velocity that would stabilize images on the retina in a stationary visual world. Therefore, these stimulus configurations are called $x 0$ and $x 2$. Limitations of the vestibular turntable and mirror galvanometer caused some deviation of the head and visual stimulus from the commanded movements; however, the head was always within $10 \%$ of the commanded velocity, and the visual stimulus was always within $17 \%$ of the head speed and within $13^{\circ}$ of exactly in phase or exactly out of phase with the head.

For each frequency of sinusoidal vestibular stimulation, $\mathrm{x} 0$ and $\mathrm{x} 2$ stimuli were alternated and each stimulus was presented for 60-90 sec. Recordings were made when the gain of the VOR was close to 1.0 , and the $\mathrm{x} 0$ and $\mathrm{x} 2$ stimuli were not presented for long enough to cause measurable changes in the gain of the VOR measured in the dark. Thus, Purkinje cell responses were recorded under conditions that cause learning, but we did not follow the changes in Purkinje cell responses as the gain of the VOR was modified. To maintain a constant level of alertness and to keep the stimulus roughly centered in the visual field during vestibular stimulation, monkeys were rewarded at intervals of 1.5-4 sec for keeping their gaze within $\pm 10^{\circ}$ of the center of the visual stimulus.

Electrodes were introduced daily and driven by a hydraulic microdrive through the cerebral cortex toward the cerebellum. Entry into the cerebel-

$$
\text { ……‥ }
$$


lum was recognized by a large increase in background activity and the presence of the complex spikes of Purkinje cells. Entry into the floccular complex was signaled by the presence of background activity related to eye movements. Because of the presence of clear landmarks such as the vestibular nerve and bone and because of the extensive experience of our laboratory with recording in this area, histology was not conducted.

The responses of individual Purkinje cells were isolated by careful movements of the electrode and then followed for periods of up to 45 min. To obtain a reasonable sample of non-HGVP Purkinje cells, we attempted to isolate all Purkinje cells that appeared to show modulation of simplespike activity during either horizontal pursuit with the head stationary or cancellation of the VOR. Voltages related to eye position, eye velocity, and head velocity were recorded during the experiment at $500 \mathrm{~Hz}$ per channel. The eye velocity signal was obtained by using an analog circuit to differentiate the eye position output from the coil electronics, and the head velocity signal was obtained from a tachometer attached to the shaft of the turntable. The simple-spike activity of Purkinje cells was recorded to the nearest $10 \mu \mathrm{sec}$ with a hardware window discriminator. In addition, unit activity was sampled at $50 \mathrm{kHz}$, and off-line spike sorting with time and amplitude windows was used to discriminate complex spikes.

The data were analyzed after the experiment by aligning the records on the negative-to-positive zero crossings of the sinusoidal head velocity or visual stimulus position. Each cycle was divided into 64 equal-length bins, and eye velocity, head velocity, simple-spike firing rate, and complexspike firing rate were averaged. The averages were subjected to Fourier analysis, and the amplitude of modulation and phase of the responses were estimated as the amplitude and phase at the fundamental frequency. For analysis of eye velocity at frequencies $\leqslant 2 \mathrm{~Hz}$, eye velocity records were edited before averaging to remove the rapid deflections caused by saccades. For frequencies $>2 \mathrm{~Hz}$, analysis of eye velocity was limited to saccade-free cycles.

\section{Results}

EYE AND IMAGE MOTION DURING STIMULI THAT INDUCE LEARNING

To evaluate the neural signals that control the induction of motor learning in the VOR, we com- pared the patterns of neural activity during visual/ vestibular stimuli that induce a decrease in the gain of the VOR with the patterns present during stimuli that induce an increase in the gain of the VOR. As illustrated in Figure 2, visual stimuli were presented during passive whole body rotation about a vertical axis. The vestibular stimulus was sinusoidal head movement with a peak-to-peak velocity of $20 \% \mathrm{sec}$, and the visual stimulus moved on a tangent screen at approximately the same speed as the head, creating either a $\mathrm{x} 0$ or $\mathrm{x} 2$ stimulus configuration. For $\mathrm{x} 0$ stimuli, the motion of the head and visual stimulus were in phase, and for $\mathrm{x} 2$ stimuli, they were $180^{\circ}$ out of phase.

During both $\mathrm{x} 0$ and $\mathrm{x} 2$ stimuli at $0.5 \mathrm{~Hz}$ (Fig. 2), the monkey used visual tracking mechanisms to match gaze position (eye position with respect to the world) to visual stimulus position. As a result, the smooth component of eye velocity was nearly unmodulated during $\mathrm{x} 0$ stimuli and was approximately twice head velocity during $x 2$ stimuli. Figure $3, \mathrm{~A}$ and $\mathrm{B}$, plots the eye movement gain and phase relative to head velocity during $x 0$ stimuli (open symbols) and $\mathrm{x} 2$ stimuli (filled symbols) at frequencies from 0.2 to $10 \mathrm{~Hz}$. The eye movements driven by the VOR during the vestibular stimuli in the dark are shown also (Xs). At the lowest frequency of $0.2 \mathrm{~Hz}$, visual tracking was nearly perfect so that the gain of the eye movements was close to zero during $\mathrm{x} 0$ stimuli and close to 2.0 during $\mathrm{x} 2$ stimuli. As frequency increased up to $\sim 3$ $\mathrm{Hz}$, visual tracking was imperfect but still present so that the gain of the eye movements was larger than the gain of the VOR during the $x 2$ stimuli and smaller than the gain of the VOR during $x 0$ stimuli. At frequencies of $3 \mathrm{~Hz}$ or above, however, the gain of the eye movements was similar during $\mathrm{x} 0$ stimuli, $x 2$ stimuli, and the VOR in the dark, indicating the ineffectiveness of visual tracking mechanisms at those frequencies. Similarly, the phase difference between eye and head velocity differed between $x 0$ and $x 2$ stimuli for low frequencies (below $-5 \mathrm{~Hz}$ ) but not at higher frequencies.

The function of visually driven tracking mechanisms is to reduce the movement of visual images on the retina. In the absence of visually driven tracking mechanisms and with a VOR gain near 1.0 , the expected amplitude and phase of retinal image motion would be equal to the amplitude and phase of visual stimulus motion. Figure 3, C and D, plots the retinal image motion present during $\mathrm{x} 0$ and $x 2$ stimuli of different frequencies. Retinal image velocity was calculated as the difference be-

$$
\text { ….... }
$$


tween visual stimulus velocity and the sum of eye and head velocity (called "gaze" velocity). As the frequency of vestibular stimulation increased from $0.2 \mathrm{~Hz}$ to $-3 \mathrm{~Hz}$, the amplitude of retinal image motion increased from a rather small value toward the amplitude of visual stimulus motion (about $\pm 11^{\circ} / \mathrm{sec}$ ). At higher frequencies, the speed of retinal image motion during $x 0$ stimuli was approximately equal to the speed of visual stimulus motion. The speed of retinal image motion during $x 2$ stimuli was higher than the speed of visual stimulus motion, because of the eye movement gain of $<1.0$. For all stimuli, retinal image motion was approximately in phase with the visual stimulus, that is, in phase with head velocity during $\mathrm{x} 0$ stimuli and $180^{\circ}$ out of phase with head velocity during $x 2$ stimuli.

Based on the data of Figure 3, we chose two stimulus frequencies for recording the neural signals present during learning. Recordings were made during $\mathrm{x} 0$ and $\mathrm{x} 2$ stimuli at $0.5 \mathrm{~Hz}$, when tracking was good and retinal image velocity was relatively small, and during $\mathrm{x} 0$ and $\mathrm{x} 2$ stimuli at 5 $\mathrm{Hz}$, when tracking was ineffective and retinal image velocity was large. Previously, we showed that each of these stimulus conditions, if continued for several hours, caused large and appropriately directed decreases or increases in the gain of the VOR (Raymond and Lisberger 1996a). Moreover, the behavioral experiments suggested the existence of two components of learning in the VOR that were differentially induced by the high frequency $(5 \mathrm{~Hz})$ and low frequency $(0.5 \mathrm{~Hz})$ stimuli.

\section{SUBCLASSIFICATION OF PURKINJE CELLS}

Purkinje cells in the floccular complex receive inputs from mossy fibers carrying vestibular, eye movement (efference copy), and visual (image motion) signals (Precht and Llinas 1969; Miles et al. 1980a; Langer et al. 1985; Graf et al. 1988; Stone and Lisberger 1990). When a Purkinje cell was isolated, it was first categorized according to its eye and head velocity sensitivity, as has been done previously for neurons in the circuit for the VOR (Lisberger and Fuchs 1974, 1978; Miles and Fuller 1974, 1975; Noda and Suzuki 1979; Miles et al. 1980a; Waespe and Henn 1981; Buttner and Waespe 1984; Lisberger et al. 1994a,b,c). Two tracking conditions were used to estimate separately the eye and head velocity inputs to the Purkinje cells. The eye velocity input was analyzed by recording simple-spike firing rate as the monkey tracked $0.5-\mathrm{Hz}$ sinusoidal target motion along the horizontal axis $\left( \pm 31.4^{\circ} / \mathrm{sec}\right)$ with the head stationary ("pursuit"). For the Purkinje cell in Figure 4, simple-spike firing rate peaked just after peak eye velocity away from the side of recording (vertical broken line). This cell and all cells whose simplespike firing rate peaked within $90^{\circ}$ of peak eye velocity away from the side of recording were clas-

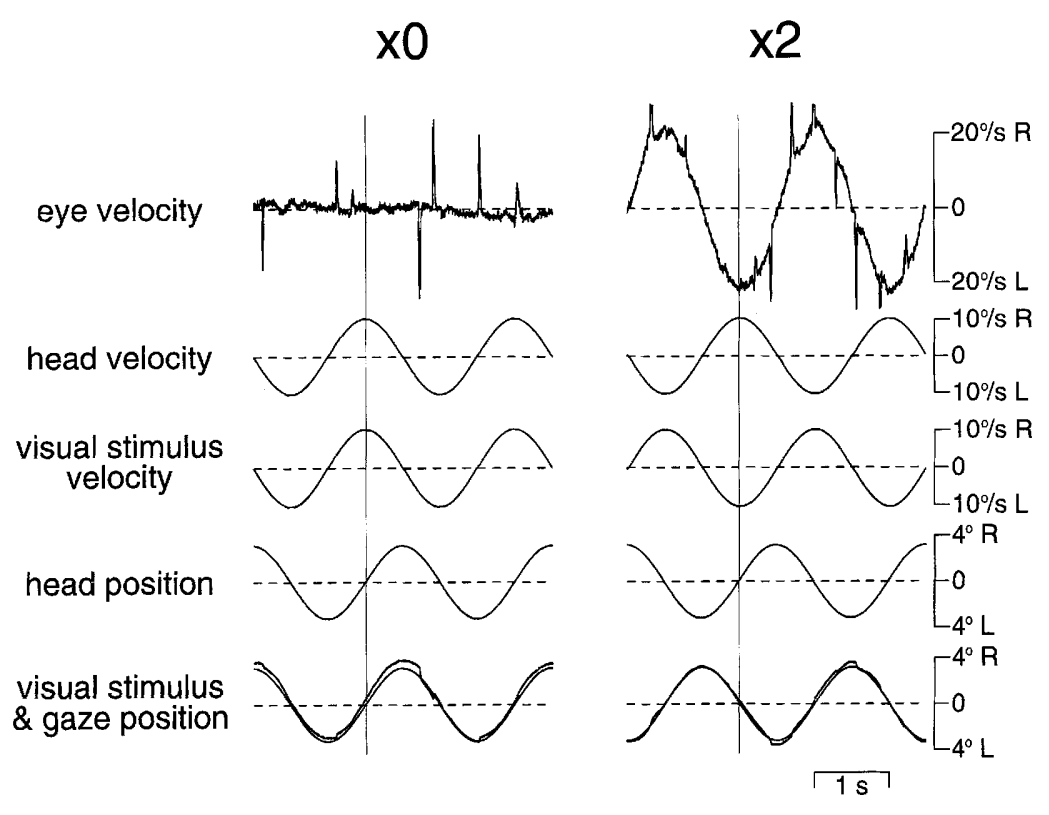

Figure 2: Raw data showing eye movements during visual and vestibular stimuli that induce learned decreases $\left(x_{0}\right)$ and increases $(x 2)$ in the gain of the VOR. From top to bottom, the traces are eye velocity with respect to the orbit, angular head velocity in space, visual stimulus velocity in space, head position in space, and visual stimulus/gaze position in space. Gaze position was computed electronically as the sum of head position in space plus eye position in the orbit. In all traces, upward deflections represent rightward position or velocity $(\mathrm{R})$; downward deflections represent leftward position or velocity $(\mathrm{L})$. The brief deflections in the eye velocity traces are caused by saccadic eye movements: Their amplitudes have been cropped. The frequency of the sine waves is $0.5 \mathrm{~Hz}$. The vertical lines mark the time of peak rightward head velocity.

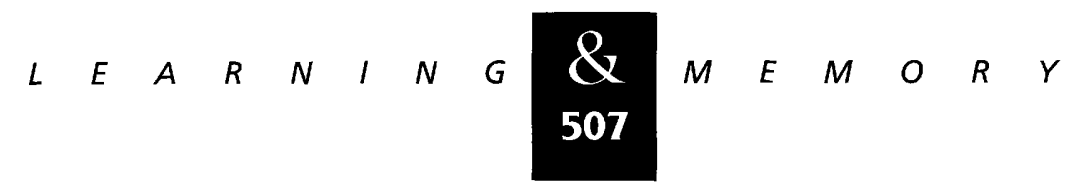




\section{Raymond and Lisberger}

Figure 3: Quantitative summary of the effect of the frequency of sinusoidal visual/vestibular rotation on eye movement and retinal image movement. (A) Eye movement gain, computed as eye speed divided by head speed, is plotted as a function of stimulus frequency. $(B)$ The phase difference between eye velocity and head velocity is plotted as a function of stimulus frequency. By convention, a VOR exactly out of phase with head movement is defined as having a phase of zero. Likewise, eye movements that were exactly out of phase with head movement during $\times 0$ and $\times 2$ stimuli are plotted as having a phase of zero. ( $C$ ) The amplitude of retinal image velocity is plotted as a function of stimulus frequency. (D) The phase shift between retinal image velocity and head velocity is plotted as a function of stimulus frequency. Image velocity in phase with head velocity is defined as having a phase of zero. Image velocity exactly out of phase with head velocity is defined as having a phase of $180^{\circ}$. Open symbols show results for $x 0$ stimuli, filled symbols show results for $\times 2$ stimuli, and $X$ s show eye movements during the VOR in the dark. (Squares) Monkey A; (circles) monkey D. All stimuli had an amplitude of $\pm 10 \%$ sec.
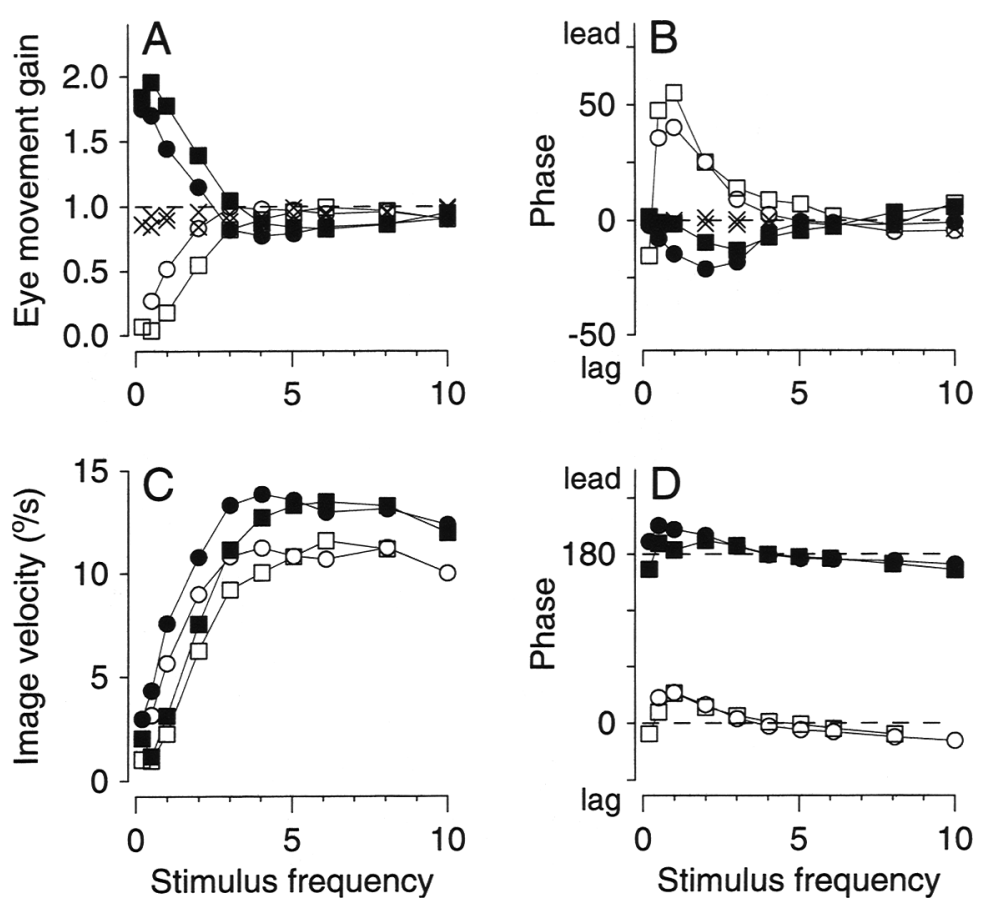

sified as "Eye contraversive" (E-c). Purkinje cells whose simple-spike firing rate peaked within $90^{\circ}$ of peak eye velocity toward the side of recording were classified as "Eye ipsiversive" (E-i). Purkinje cells that did not exhibit at least \pm 10 spikes/sec modulation of simple-spike firing rate during smooth pursuit eye movements were classified as non-eye movement and labeled $\sim \mathrm{E}$.
Figure 4: Averaged simple-spike responses of a representative E-C, V-i Purkinje cell during the smooth pursuit and VOR cancellation tracking conditions used to categorize the cells. From top to bottom, the traces are histograms showing the simple-spike firing rate, horizontal eye velocity, target velocity, head velocity, and image velocity. Each cycle contained 64 bins--because the period of the sinusoidal stimulus was $2 \mathrm{sec}$, this corresponds to a bin width of $31.25 \mathrm{msec}$. As indicated by the arrows, upward deflections represent ipsiversive motion (I) and downward deflections represent contraversive motion (C). In the panel at left (pursuit), the vertical broken line shows the time of peak contraversive eye and target velocity. In the panel at right (VOR cancellation), the vertical broken line shows the time of peak ipsiversive head velocity.
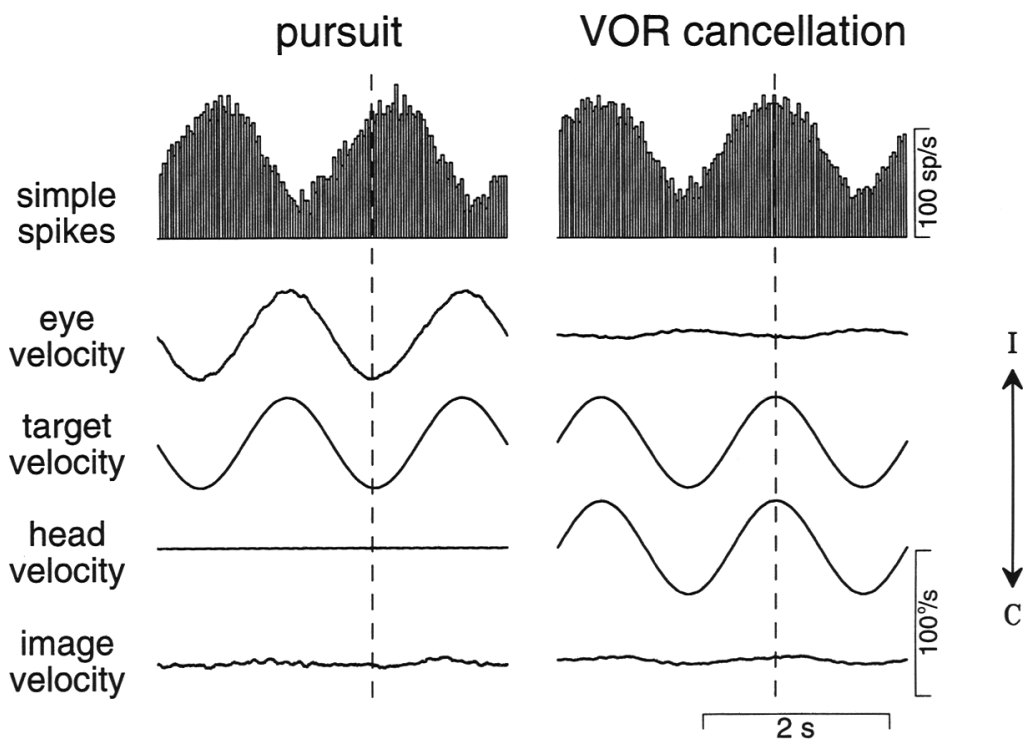

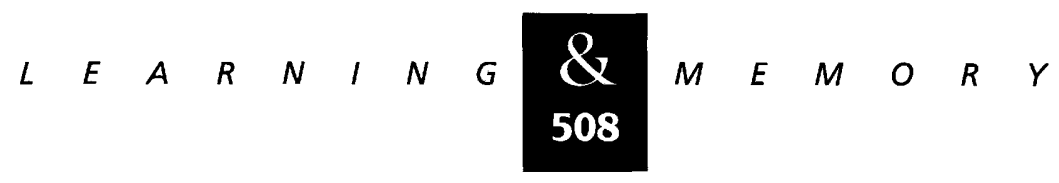


Purkinje cells were further categorized according to the head velocity component of simple-spike firing rate, which was analyzed by recording from the Purkinje cells as the monkey canceled its VOR by tracking a target that moved exactly with him during $0.5 \mathrm{~Hz}, \pm 31.4^{\circ} / \mathrm{sec}$ sinusoidal head rotation. During cancellation of the VOR, inputs from the eye movement feedback and visual image motion pathways should modulate little as a function of the vestibular stimulus. Hence, modulation of Purkinje cell firing rate during head rotation should provide an estimate of the vestibular inputs. In the Purkinje cell in Figure 4, simple-spike firing rate peaked close to peak head velocity toward the side of recording. It and other Purkinje cells whose simple-spike firing during cancellation of the VOR peaked within $90^{\circ}$ of peak head velocity toward the side of recording were classified as "Vestibular ipsiversive" (V-i). Purkinje cells whose simplespike firing rate peaked within $90^{\circ}$ of peak head velocity away from the side of recording were classified as "Vestibular contraversive" (V-c). Purkinje cells that did not exhibit modulation of their simple-spike firing rate of at least \pm 10 spikes/sec during cancellation of the VOR were classified as nonvestibular $(\sim V)$.

Figure 5 summarizes the basic response properties of our entire sample of Purkinje cells by plotting the amplitude of modulation of simple-spike firing rate during cancellation of the VOR as a function of that during horizontal smooth pursuit eye movement. Points representing E-i responses plot to the right of the vertical axis, points representing E-c responses plot to the left of the vertical axis, and points representing $\sim E$ responses (modulation less than \pm 10 spikes/sec) plot close to the vertical axis, between the vertical broken lines. Points representing $\mathrm{V}-\mathrm{i}$ responses (triangles) plot above the horizontal axis, points representing V-c responses (squares) plot below the horizontal axis, and points representing $\sim \mathrm{V}$ responses (circles) plot close to the horizontal axis, between the horizontal broken lines. According to conventions established by prior studies, the Purkinje cells that plot in the upper right quadrant of Figure 5 (E-i, V-i cells; open triangles) were classified as HGVPs. Their responses during $\mathbf{x} 0$ and $\mathbf{x} 2$ stimuli are reported elsewhere (Raymond and Lisberger 1996b) and are not included in this analysis. In the present study, we examine all other Purkinje cells in the floccular complex that exhibited modulation of simple-spike firing rate of at least \pm 10 spikes/sec during either horizontal smooth pursuit or cancel-

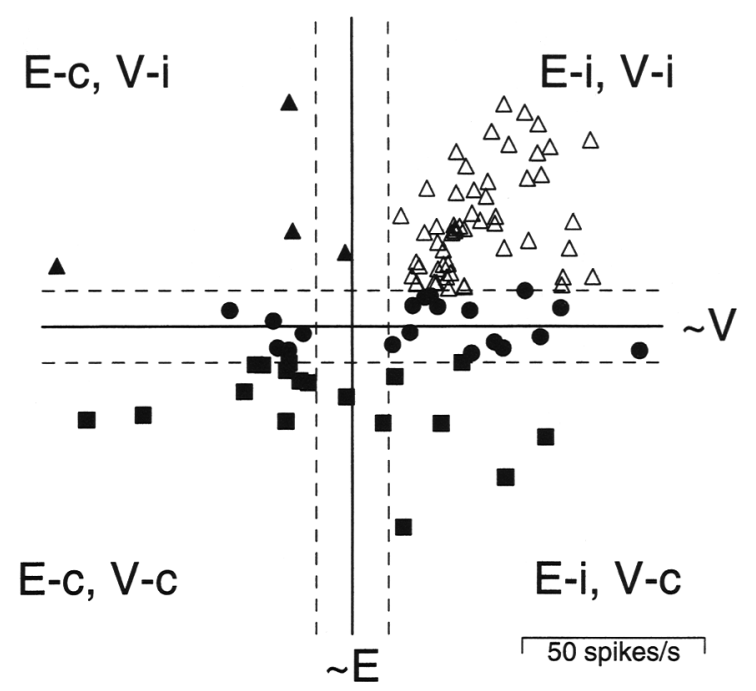

Figure 5: Categorization of the full sample of Purkinje cells recorded in the floccular complex according to their eye movement and vestibular inputs. For each Purkinje cell recorded, the amplitude of the modulation of simple-spike firing rate during cancellation of the VOR is plotted as a function of the amplitude of modulation of simple-spike firing rate during horizontal smooth pursuit eye movement. Points above the horizontal axis represent Purkinje cells whose simple-spike firing rate increased during ipsiversive head velocity during cancellation of the VOR (V-i cells; triangles). Points below the horizontal axis represent Purkinje cells whose simplespike firing rate increased during contraversive head velocity during cancellation of the VOR (V-c cells; squares). Points to the right of the vertical axis represent E-i Purkinje cells, whose simple-spike firing rate increased during ipsiversive eye velocity during smooth pursuit. Points to the left of the vertical axis represent E-c Purkinje cells, whose simple-spike firing rate increased during contraversive eye velocity during smooth pursuit. Points between either the vertical broken lines or the horizontal broken lines represent Purkinje cells whose simple-spike modulation was less than \pm 10 spikes $/ \mathrm{sec}$ during smooth pursuit eye movement ( $\sim$ E cells) or during cancellation of the VOR $(\sim \vee$ cells; circles $)$. Cells whose simple spike modulation was less than \pm 10 spikes/sec during both tracking conditions were omitted from the graph and the analysis. The E-i, V-i cells in the upper right quadrant $(\triangle)$, also known as HGVPs, are analyzed elsewhere (Raymond and Lisberger 1996b). Symbol shapes in this graph are used throughout subsequent figures to distinguish the different vestibular classifications of the Purkinje cells.

lation of the VOR (filled symbols). Of 41 Purkinje cells meeting these criteria, 39 also were tested during smooth pursuit of target motion along the vertical axis. In only 2 of these 39 cells was modu-

$$
\begin{array}{llllllll}
L & E & A & R & N & I & N & G \\
\begin{array}{l}
\boldsymbol{Q} \\
509
\end{array} & M & E & M & O & R & Y
\end{array}
$$


lation of simple-spike firing rate larger during vertical pursuit than during both horizontal pursuit and cancellation of the horizontal VOR. Thus, it is reasonable to assume that the non-HGVP Purkinje cells reported here might participate in horizontal eye movements.

\section{CORRELATION OF COMPLEX-SPIKE ACTIVITY WITH} THE VESTIBULAR STIMULUS

First, we examined the possibility that comparison of the climbing fiber input to the Purkinje cells with the vestibular stimulus might provide information about whether to increase or decrease the gain of the VOR. This combination of signals has been hypothesized to contribute to motor learning in the VOR by controlling cerebellar longterm depression (LTD) of synapses from vestibular parallel fibers to Purkinje cells (Marr 1969; Albus 1971; Ito 1972, 1982). In addition, climbing fiber collaterals and vestibular inputs could converge at the site of plasticity in the vestibular nucleus and contribute to the induction of plasticity there (Fig. 7 , inset, below). We monitored the climbing fiber inputs by recording the complex spikes in Purkinje cells, which occur each time there is an action potential in the climbing fiber input to the cell.

The histograms in Figure 6 illustrate the relationship between the vestibular stimulus and the complex spikes of one E-c, V-c Purkinje cell during stimuli that induce learning. Although the signals are noisy, the phase of complex-spike firing clearly depends on whether the recordings were made during $\mathrm{x} 0$ or $\mathrm{x} 2$ stimuli. At $0.5 \mathrm{~Hz}$, complex-spike activity was roughly in phase with ipsiversive head velocity during $\mathrm{x} 0$ stimuli and roughly in phase with contraversive head velocity during $\mathrm{x} 2$ stimuli. At $5 \mathrm{~Hz}$, the phase relationship was reversed so that complex spikes were in phase with contraversive head velocity during $\mathrm{x} 0$ stimuli and with ipsiversive head velocity during $\mathrm{x} 2$ stimuli.

Figure 7 summarizes the complex-spike responses recorded in the various classes of Purkinje cells during stimuli that induce learning. Responses are plotted in polar coordinates, at a distance from the origin corresponding to the amplitude of response modulation and an angle corresponding to the phase of peak complex-spike activity relative to the vestibular stimulus. Responses in phase with peak ipsiversive head velocity are plotted to the right of the origin, responses in phase with peak contraversive head velocity are plotted to the left of the origin, and clockwise rotation around the graph represents increased phase lead. An individual Purkinje cell contributed two symbols for each stimulus frequency, an open symbol for the $\mathrm{x} 0$ stimulus and a filled symbol for the $\mathrm{x} 2$ stimulus. The shape of the symbols reflects the vestibular classification of the Purkinje cells, as in Figure 5. Inspection of the four plots in Figure 7 reveals that there was fairly clear separation of the responses to $\mathrm{x} 0$ stimuli (open symbols) and $\mathrm{x} 2$ stimuli (filled symbols) but no clear grouping according to the vestibular classification of the Purkinje cell (symbol shape). Because there were no clear differences between the complex-spike responses in the $\mathrm{V}$-i cells (triangles), $\sim \mathrm{V}$ cells (circles), and V-c cells
Figure 6: Averages showing the correlation of the complex-spike firing of an individual $E-C, V-c$ Purkinje cell with the vestibular stimulus during $x 0$ and $x 2$ stimuli at $0.5 \mathrm{~Hz}$ and $5 \mathrm{~Hz}$. From top to bottom, the traces are histograms showing complexspike firing during $x 0$ stimuli, histograms showing complex-spike firing during $x 2$ stimuli, and head velocity. The two pairs of vertical broken lines show times of peak contraversive (C) and ipsiversive (I) head velocity. Each cycle was divided into 64 bins so that the bin width was $31.25 \mathrm{msec}$ for sinusoidal vestibular stimulation at $0.5 \mathrm{~Hz}$ and $3.125 \mathrm{msec}$ for sinusoidal vestibular stimulation at $5 \mathrm{~Hz}$.

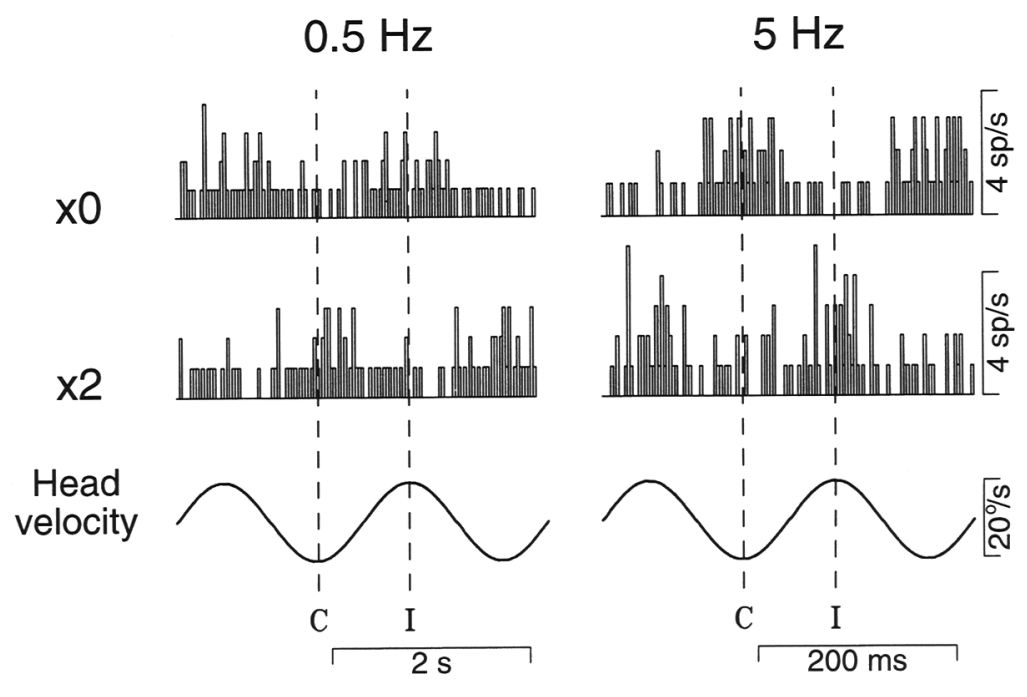

$\begin{array}{lllllllll}N & \mathbf{Q Z}_{5} & M & E & M & O & R & Y\end{array}$ 


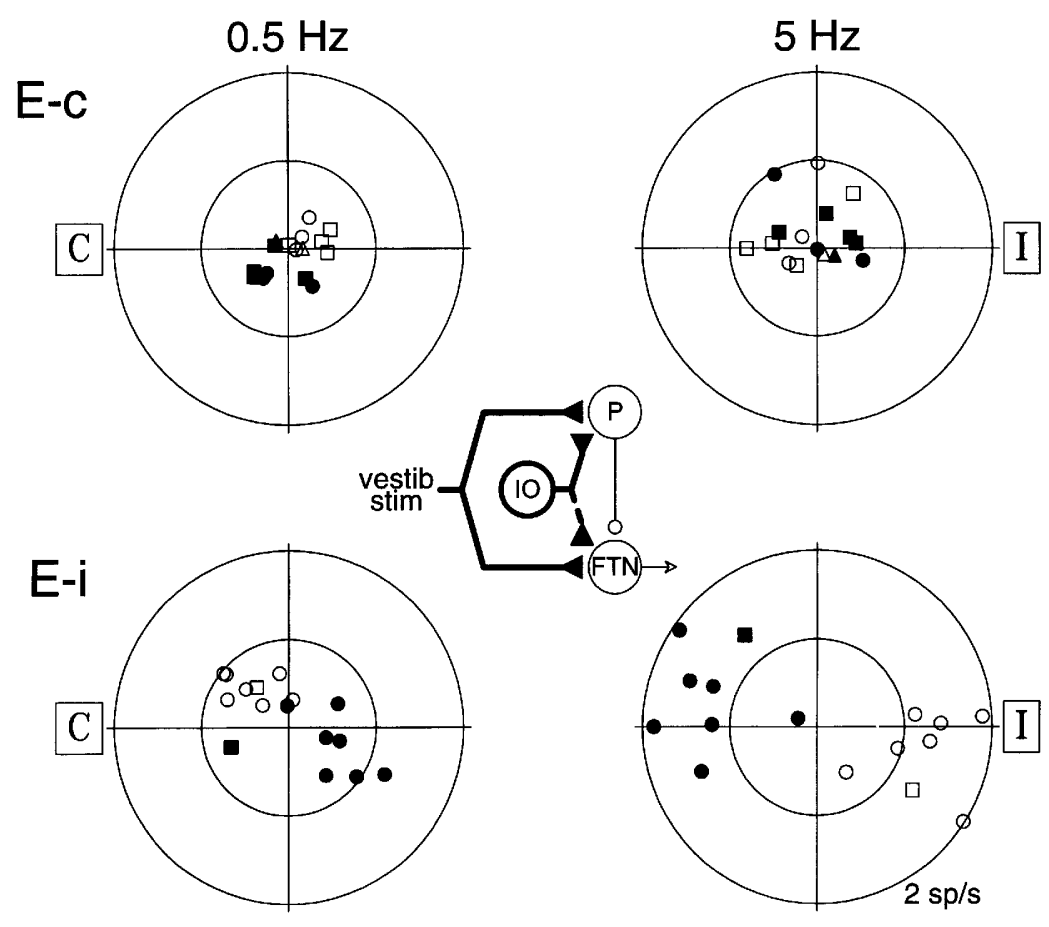
siversive head velocity (I) are plotted to the right of the origin, responses in phase with peak contraversive head velocity (C) are plotted to the left of the origin, and clockwise rotation around the graph represents increased phase lead. The inner and outer circles represent amplitudes of complex-spike firing rate of \pm 1 and \pm 2 spikes/sec. (Triangles) V-i Purkinje cells; (circles) $\sim$ V Purkinje cells; (squares) V-c Purkinje cells. (squares), all of the Purkinje cells can be discussed as two groups, E-c cells (top plots) and E-i cells (bottom plots). Complex spikes could not be reliably discriminated from the simple spikes in any of the three $\sim$ E cells recorded.

During any particular stimulus, the timing of the complex-spike responses relative to the vestibular stimulus differed in E-c and E-i Purkinje cells. Also, the amplitude of modulation of complex-spike activity was generally smaller in E-c than in E-i cells. Nevertheless, two observations can be made for both classes of Purkinje cells. First, for each frequency of vestibular stimulus, the complex-spike responses to $\mathrm{x} 0$ and $\mathrm{x} 2$ stimuli form distinguishable, almost nonoverlapping populations that are separated by $\sim 180^{\circ}$ of phase shift and therefore plot on opposite sides of each diagram. Two E-c cells were an exception to this generalization at $5 \mathrm{~Hz}$, however, both of these cells were on the border between classification as E-c and E-i cells: their simple-spike responses lagged contraversive eye velocity by $69^{\circ}$ and $80^{\circ}$ during sinusoidal smooth pursuit eye movements. Second, for a particular required change in the VOR, the phase
Figure 7: Polar plots summarizing the relationship between the complex-spike responses and the vestibular stimulus during stimuli that induce motor learning in the VOR. Center diagram illustrates the convergence of the climbing fiber signals (revealed by the complex spikes) and the vestibular signals at the two putative sites of plasticity in the circuit for the VOR. The responses of E-c Purkinje cells are plotted in the top two graphs, and the responses of E-i Purkinje cells are plotted in the bottom two graphs. Responses during vestibular rotation at 0.5 and $5 \mathrm{~Hz}$ are plotted at left and right, respectively. Each plot compares responses during $\mathrm{x} 0$ stimuli (open Each point represents the complex-spike activity recorded in a single Purkinje cell, plotted in polar coordinates with the distance from the origin corresponding to the amplitude of response modulation and the angle corresponding to the phase shift between complex-spike activity and head velocity. Responses in phase with peak ip-
hase with peak contraversive head velocity symbols) and $\mathrm{x} 2$ stimuli (filled symbols).

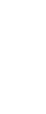


in the various classes of Purkinje cells might provide consistent information about whether to increase or decrease the gain of the VOR. The combination of simple-spike and vestibular signals potentially could drive plasticity in the vestibular nucleus (Miles and Lisberger 1981) or induce Hebbian (or anti-Hebbian) plasticity in the synapses from vestibular parallel fibers onto Purkinje cells (Fig. 9, inset, below).

The histograms in Figure 8 show the simplespike responses in one E-i, $\sim \mathrm{V}$ Purkinje cell during vestibular stimulation at 0.5 and $5 \mathrm{~Hz}$. At $0.5 \mathrm{~Hz}$, the simple-spike responses depended on whether the recordings were made during $\mathrm{x} 0$ or $\mathrm{x} 2$ stimuli. During $x 2$ stimuli, simple-spike activity increased during contraversive head velocity (which coincided with ipsiversive eye velocity), but during $x 0$ stimuli, there was little modulation of simple-spike firing. At $5 \mathrm{~Hz}$, the simple-spike firing rate of the Purkinje cell was modulated during both $\mathrm{x} 0$ and $\mathrm{x} 2$ stimuli, but the correlation between simple-spike firing rate and head velocity did not depend on the stimulus configuration (simple spikes were approximately in phase with contraversive head velocity during both $\mathrm{x} 0$ and $\mathrm{x} 2$ stimuli) and therefore did not provide information about whether to increase or decrease the gain of the VOR.

The polar plots in Figure 9 summarize the correlation of Purkinje cell simple-spike activity with the vestibular stimulus during stimuli that induce motor learning in the VOR. The results were similar regardless of whether the Purkinje cell was V-c, $\mathrm{V}-\mathrm{i}$, or $\sim \mathrm{V}$ (squares, triangles, and circles, respec- tively). Therefore the E-c cells are treated together as a single group (top plots), and the E-i cells are treated as a separate group (bottom plots). At 0.5 $\mathrm{Hz}$, comparison of simple-spike activity with head velocity discriminated $\mathrm{x} 0$ from $\mathrm{x} 2$ stimuli in both the E-i and E-c Purkinje cells. When the gain of the VOR needed to decrease ( $x 0$ stimuli, open symbols), simple-spike firing rate was unmodulated during the vestibular stimulus in both E-c and E-i cells. When the gain of the VOR needed to increase (x2 stimuli, filled symbols), simple-spike firing rate was in phase with ipsiversive head velocity in the E-c cells and in phase with contraversive head velocity in the E-i cells. In contrast, at $5 \mathrm{~Hz}$ there was considerable overlap in the responses to $\mathrm{x} 0$ and $\mathrm{x} 2$ stimuli. Simple spikes were in phase with ipsiversive head velocity in the E-c cells and in phase with contraversive head velocity in the E-i cells, regardless of whether the stimulus configuration called for an increase or decrease in the gain of the VOR. Therefore, the correlation of E-c and E-i Purkinje cell simple-spike activity with the vestibular stimulus contained information that could be used to guide learning in the VOR at low frequencies but not at high frequencies.

In the three cells with simple-spike responses during cancellation of the VOR but less than \pm 10 spikes/sec of modulation of simple spike firing during horizontal pursuit (two $\sim \mathrm{E}, \mathrm{V}-\mathrm{c}$ cells and one $\sim \mathrm{E}, \mathrm{V}-\mathrm{i}$ cell), the correlation between the simple spikes and the vestibular stimulus did not discriminate $\mathrm{x} 0$ from $\mathrm{x} 2$ stimuli at $0.5 \mathrm{~Hz}$ or $5 \mathrm{~Hz}$ (data not shown).
Figure 8: Averages showing the correlation of the simple-spike firing of an individual $E-i, \sim V$ Purkinje cell with the vestibular stimulus during $x 0$ and $\times 2$ stimuli at $0.5 \mathrm{~Hz}$ and $5 \mathrm{~Hz}$. From top to bottom, the traces are histograms showing simplespike firing during $\mathrm{x} 0$ stimuli, histograms showing simple-spike firing during $\times 2$ stimuli, and head velocity. The two pairs of vertical broken lines show times of peak contraversive (C) and ipsiversive (I) head velocity. Each cycle was divided into 64 bins so that the bin width was $31.25 \mathrm{msec}$ for sinusoidal vestibular stimulation at $0.5 \mathrm{~Hz}$ and $3.125 \mathrm{msec}$ for sinusoidal vestibular stimulation at $5 \mathrm{~Hz}$.

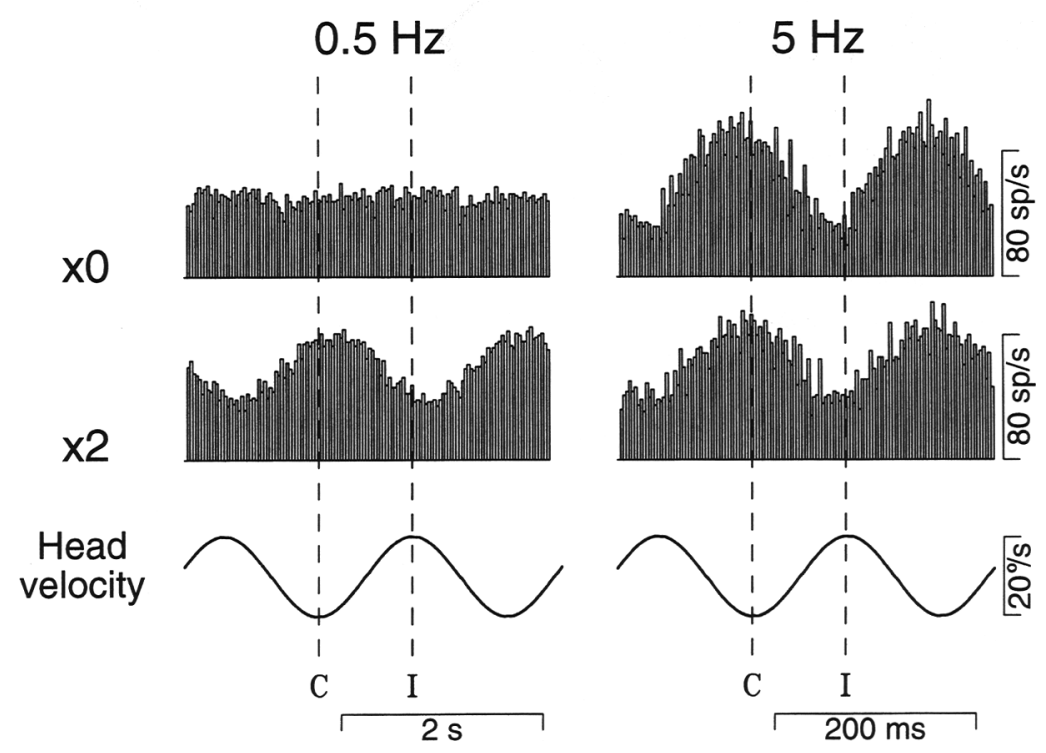

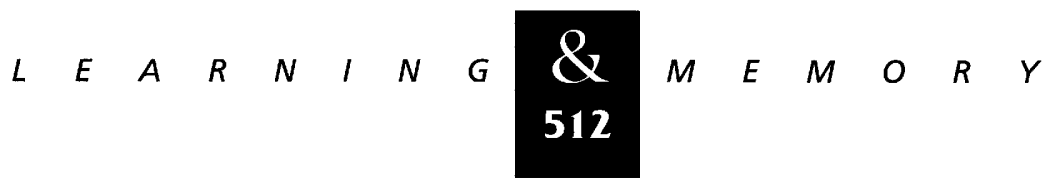




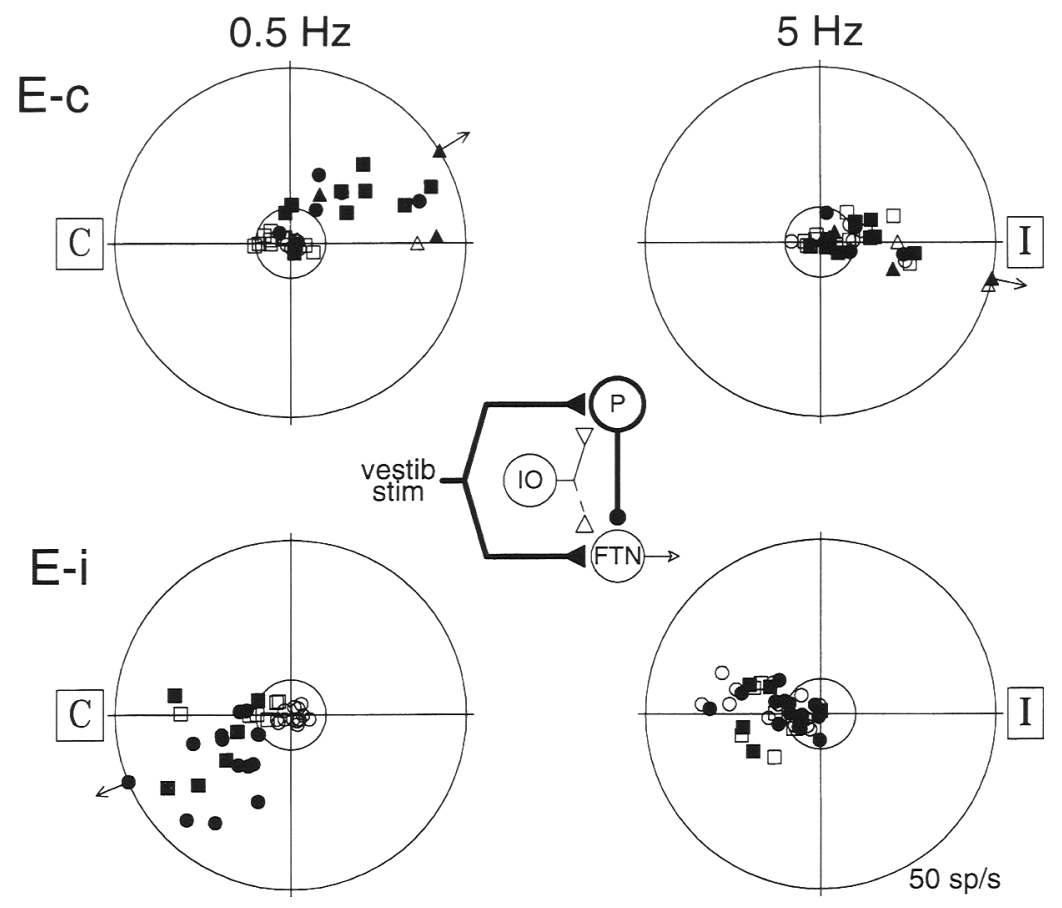

Figure 9: Polar plots summarizing the relationship between the simple-spike responses and the vestibular stimulus during stimuli that induce learning. Center diagram illustrates the convergence of the vestibular and simple-spike signals at the two putative sites of plasticity in the circuit for the VOR. Responses of E-c Purkinje cells are plotted in the upper two graphs, and responses of E-i Purkinje cells are plotted in the lower two graphs. Responses during vestibular rotation at 0.5 and $5 \mathrm{~Hz}$ are plotted at left and right, respectively. Each plot compares responses during $\mathrm{x} 0$ stimuli (open symbols) and $\mathrm{x} 2$ stimuli (filled symbols). Each point represents the simple-spike activity recorded in a single Purkinje cell, plotted in polar coordinates with the distance from the origin corresponding to the amplitude of response modulation and the angle corresponding to the phase shift between simple-spike activity and head velocity. Responses in phase with peak ipsiversive head velocity (I) are plotted to the right of the origin, responses in phase with peak contraversive head velocity $(C)$ are plotted to the left of the origin, and clockwise rotation around the graph represents increased phase lead. The inner and outer circles represent amplitudes of modulation of simple-spike firing rate of \pm 10 and \pm 50 spikes/sec. Points marked by arrows exhibited simple-spike modulation of greater than 50 spikes/sec, but are plotted at the correct angle. (Triangles) V-i Purkinje cells; (circles) V Purkinje cells; (squares) V-c Purkinje cells.

\section{CORRELATION OF COMPLEX-SPIKE ACTIVITY WITH SIMPLE-SPIKE ACTIVITY}

Because simple-spike activity and climbing fiber inputs are both present at each of the putative sites of plasticity, the correlation between these two signals potentially could guide the induction of plasticity also. Side-by-side inspection of Figures 7 and 9 reveals that for both E-c and E-i cells, comparison of climbing-fiber and simple-spike signals could provide some information about whether to increase or decrease the gain of the VOR. The correlations are most easily seen in the E-i Purkinje cells because they exhibit larger modulations of complex-spike firing rate; however, the same general conclusions apply to the E-c cells. During $5 \mathrm{~Hz}$ vestibular stimulation, complex spikes in E-i cells were in phase with the simple spikes during the $\mathrm{x} 2$ stimulus but were $180^{\circ}$ out of phase with the simple spikes during the $\mathrm{x} 0$ stimulus. During vestibular stimulation at $0.5 \mathrm{~Hz}$, complex and simple spikes in the E-i cells were out of phase for $\mathrm{x} 2$ stimuli, and simple-spike firing was unmodulated during climbing fiber modulation for $\mathbf{x} 0$ stimuli. By discriminating the $\mathrm{x} 0$ from the $\mathrm{x} 2$ configuration at each stimulus frequency, the correlation between the complex spikes and simple spikes provides some information that could be useful for motor learning in the VOR. However, the phase relationship between complex-spike and simple-spike activity during a particular stimulus configuration was not consistent across stimulus frequency. For the E-i Purkinje cells, complex-spike and simplespike firing were in phase during $\times 2$ stimuli at $5 \mathrm{~Hz}$ and out-of-phase during $x 2$ stimuli at $0.5 \mathrm{~Hz}$. Thus, the relative timing of the simple and complex spikes does not provide useful information about whether to increase or decrease the gain of the VOR without taking into account the effect of frequency on the phase shift between simple-spike and complex-spike firing.

\section{Discussion}

\section{NEURAL LEARNING RULES}

We have placed constraints on the neural learning rules in the cerebellum by recording the

$$
\text { ……‥ }
$$


signals present during motor learning in the VOR. The basic behavioral learning rule for the VOR is well known. The conjunction of head turns and image motion causes motor learning. If image motion is consistently in the same direction as head motion, then the learned change is a decrease in the gain of the VOR; if image motion is in the opposite direction from head motion, then the learned change is an increase in the gain of the VOR. Neural instantiation of this behavioral learning rule presumably involves the convergence of signals in vestibular and visual sensory pathways on the sites of plasticity. Because it is the correlation of vestibular and visual stimuli that drives learning, presumably it is also the correlation, or pattern, of activity across visual and vestibular neural pathways that drives learning. Our goal has been to evaluate which patterns of neural activity can drive the induction of plasticity in the circuit for the VOR by examining the patterns of activity present in vivo during learning with natural stimuli.

Our analysis considered three neural signals: vestibular inputs, activity in climbing fibers, and simple spikes in Purkinje cells. Only the last of these signals was recorded directly. Activity in the climbing fiber input to a Purkinje cell was inferred by recording the characteristic complex spikes that are produced in Purkinje cells in a one-to-one manner by spikes in a climbing fiber. Activity in the vestibular input pathways to the putative sites of plasticity was not recorded. Instead, we compared $\mathrm{x} 0 / \mathrm{x} 2$ stimulus pairs at a particular frequency, in which the vestibular stimulus was identical. We assumed that the neural representation of the vestibular stimulus was the same for the $\mathrm{x} 0$ and $\mathrm{x} 2$ stimuli at a particular frequency and that it was therefore reasonable to evaluate the climbing fiber and Purkinje cell simple-spike responses relative to the vestibular stimulus itself. We thought it made sense to perform this analysis even on the $\sim \mathrm{V}$ Purkinje cells because of the possibility that these neurons could receive a vestibular parallel fiber input that is either weak or for other reasons not revealed during cancellation of the VOR at $0.5 \mathrm{~Hz}$ and because the output of the $\sim \mathrm{V}$ Purkinje cells could converge on FTNs that receive a convergent vestibular input.

We used two criteria for evaluating whether a pair of neural signals could provide suitable guidance for a cellular mechanism of plasticity. First, for a given vestibular stimulus, the correlation between the pair of signals should depend on whether head turns were delivered during stimulus conditions that induce a decrease in the gain of the VOR or during stimulus conditions that induce an increase in the gain of the VOR. For example, two signals that are in phase during $\mathrm{x} 0$ stimuli and out of phase during $\mathrm{x} 2$ stimuli would be suitable to guide plasticity. Conversely, patterns of activity that are the same during $\mathrm{x} 0$ and $\mathrm{x} 2$ stimuli cannot serve as the error signals responsible for the induction of different changes in behavior by $\mathrm{x} 0$ and $\mathrm{x} 2$ stimuli. Second, for a given required change in the gain of the VOR (i.e., increase or decrease), the same correlation between signals should persist across stimulus frequency. Suppose, for example, that a cellular mechanism relies on the temporal conjunction of two signals to induce a decrease in the gain of the VOR. Then, those signals should be in phase during x0 stimuli at both $0.5 \mathrm{~Hz}$ and $5 \mathrm{~Hz}$.

None of the three pairs of signals evaluated in the present sample of non-HGVPs or in our previous study of HGVPs met both of these stringent criteria in a straightforward way. Comparison of Purkinje cell simple-spike firing rate with the vestibular stimulus met the first criterion of discriminating $\mathrm{x} 0$ from $\times 2$ stimuli at low frequencies but not at high frequencies. Comparison of climbing fiber inputs with the coincident vestibular input met the first criterion for all stimulus frequencies but failed the second criterion. Comparison of climbing fiber inputs with coincident Purkinje cell simple-spike activity met the first criterion in the non-HGVPs at all frequencies but failed the second criterion, and it failed the first criterion in the HGVPs at low frequencies.

A simple change of assumptions could resolve the problems with the second criterion of providing consistent signals across stimulus frequency. Studies of associative plasticity have emphasized the role of coincident activity in convergent neural pathways. In the case of motor learning in the VOR, however, the use of coincident activity to guide learning poses a problem because the latency of visual inputs to the cerebellum is $\sim 100$ msec longer than the latency of vestibular inputs. This 100-msec latency difference should cause a phase shift of $180^{\circ}$ in the visually driven complex spike activity at $5 \mathrm{~Hz}$. It therefore accounts for the observation that during $\mathrm{x} 0$ stimuli, complex spikes of E-i Purkinje cells were in phase with contraversive head velocity at $0.5 \mathrm{~Hz}$ but were $180^{\circ}$ out of phase with contraversive head velocity at $5 \mathrm{~Hz}$. If a cellular mechanism of plasticity could compensate for this latency difference by comparing visual

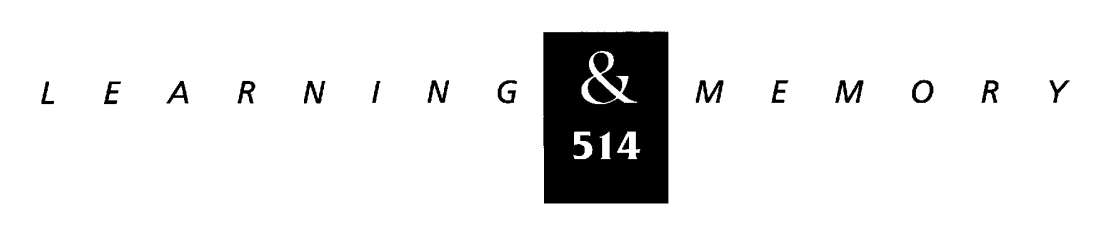


climbing fiber inputs with vestibular signals present 100 msec earlier, then this comparison could provide consistent guidance for learning across stimulus frequency. A similar assumption could resolve the apparent inconsistency across frequency in the correlation of the climbing fiber and simplespike activity.

To illustrate this point, Figure 10 replots the data from the typical Purkinje cell in Figure 6 so that the complex spikes are aligned with the vestibular stimulus that occurred 100 msec previously. When the data are plotted in this way, a "learning rule" that applies for both $0.5-\mathrm{Hz}$ and 5-Hz stimuli can be extracted readily from the signals. If peak ipsiversive head velocity is followed 100 msec later by a peak in complex-spike activity, then the gain should decrease. If peak complex spike activity follows peak contraversive head velocity by $\sim 100 \mathrm{msec}$, then the gain should increase, regardless of the stimulus frequency.

MULTIPLE SUBCLASSES OF PURKINJE CELLS HAVE THE SAME POTENTIAL TO GUIDE LEARNING

Our experiments do not address the question of the role of different subclasses of neurons in VOR performance or the question of whether a particular correlation between a pair of signals should cause synaptic potentiation or depression. Instead, we have focused on determining which pairs of neural signals contain information that could enable them to provide consistent guidance for learning, as a prelude to further investigation of the exact role of each pair of signals and each subclass of cells in learning. We found that the multiple subclasses of Purkinje cells in the floccular complex of the rhesus monkey, including the HGVPs, generally carried about the same information for guiding learning in the VOR. Therefore, our results are most consistent with the idea that all Purkinje cells in the floccular complex play a similar role in the induction of learning in the VOR. For example, in no class of Purkinje cell was the correlation between the simple spikes and the vestibular stimulus appropriate to drive learning at 5 Hz. Moreover, in all classes of Purkinje cells, the correlation of climbing fiber activity with activity in vestibular pathways discriminated $\mathrm{x} 0$ from $\mathrm{x} 2$ stimuli at each stimulus frequency tested but could provide consistent guidance for learning across stimulus frequency only if a plasticity mechanism compared climbing fiber activity at a given time with activity in vestibular inputs $100 \mathrm{msec}$ earlier. The main difference in the error signaling capacity of different classes of Purkinje cells was that in HGVPs, the correlation of simple-spike activity
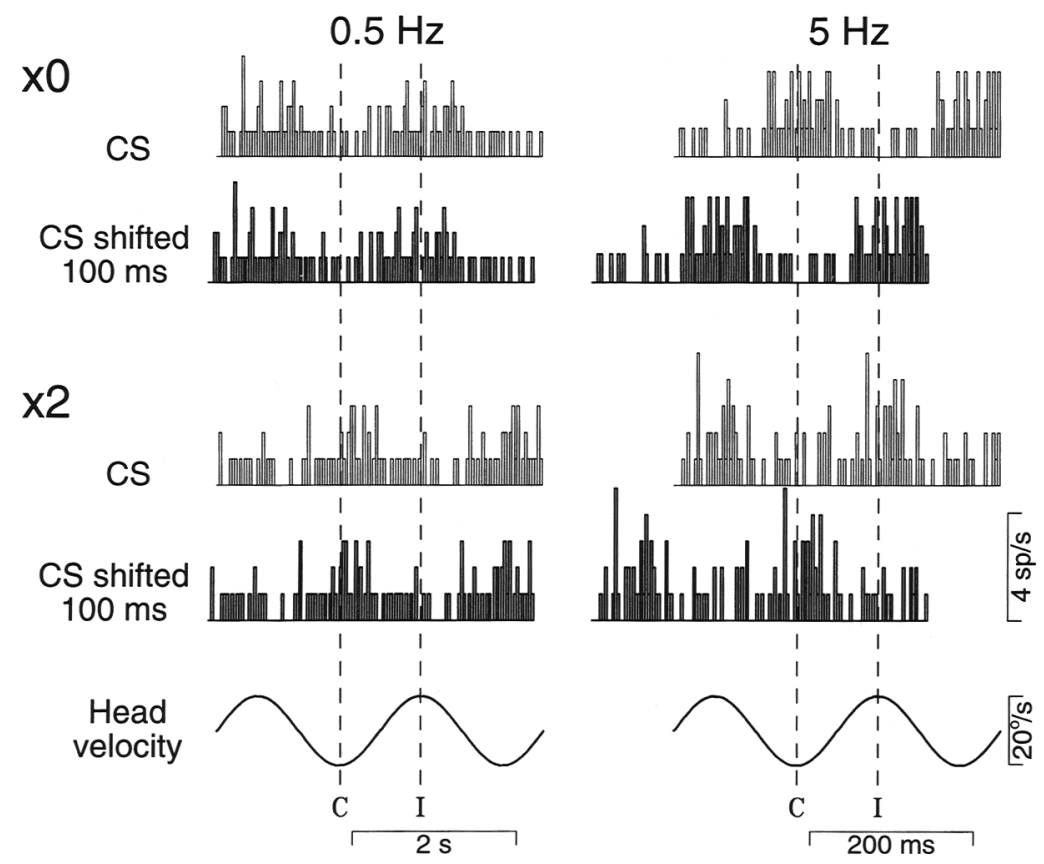

Figure 10: Complex-spike responses from the neuron in Figure 6, replotted to align complex spikes with the vestibular stimulus that occurred $100 \mathrm{msec}$ previously. From top to bottom, the traces are histograms showing complex-spike firing during $\mathrm{x} 0$ stimuli, histograms showing complex-spike firing during $x 0$ stimuli shifted leftward by $100 \mathrm{msec}$, histograms showing complex-spike firing during $\times 2$ stimuli, histograms showing complexspike firing during $x 2$ stimuli shifted leftward by $100 \mathrm{msec}$, and head velocity. Bin width was 31.25 msec for sinusoidal vestibular stimulation at $0.5 \mathrm{~Hz}$ and 3.125 msec for sinusoidal vestibular stimulation at $5 \mathrm{~Hz}$.

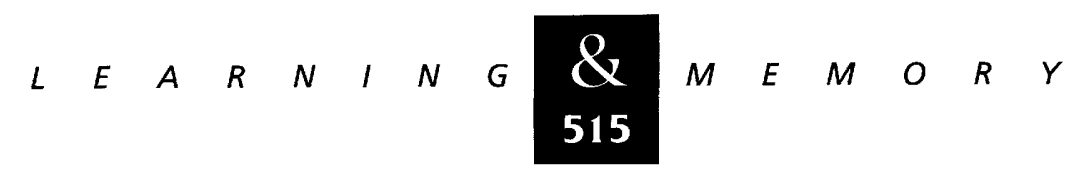


with activity in climbing fiber pathways contained appropriate information to guide learning only at high frequencies (Raymond and Lisberger 1996b), whereas in all other classes of Purkinje cells examined, the correlation of simple-spike activity with activity in climbing fiber pathways could guide learning at both stimulus frequencies tested, provided that the plasticity mechanism compared climbing fiber activity with simple-spike activity that occurred $\sim 100$ msec previously. Finally, it is difficult to evaluate the role of the $\sim$ E Purkinje cells, because such a small sample was found.

\section{CELLULAR PLASTICITY RULES}

Our results translate into several constraints on the cellular mechanisms involved in learning. First, to account for the opposite behavioral effects of $x 0$ vs. $\mathrm{x} 2$ stimuli at $5 \mathrm{~Hz}$ (Raymond and Lisberger 1996a), there must be a tight relationship between the relative timing of the neural error signals and the occurrence or even the direction of plasticity. For example, for the correlation of climbing fiber and vestibular activity to guide learning at $5 \mathrm{~Hz}$, climbing fiber activity that follows vestibular activity by $\sim 100$ msec must produce opposite cellular and synaptic changes or at least have a significantly different effectiveness than simultaneous climbing fiber and vestibular activity. A plasticity mechanism that produced identical cellular changes in response to a climbing fiber response that came $100 \mathrm{msec}$ after the vestibular input (i.e., lagged by $180^{\circ}$ at $5 \mathrm{~Hz}$ ) as it did in response to a climbing fiber response that was coincident with the vestibular input would produce identical changes in the circuit for the VOR in response to $\mathrm{x} 0$ and $\mathrm{x} 2$ stimuli at $5 \mathrm{~Hz}$ (Fig. 7). This prediction disagrees with our behavioral study showing appropriate changes in the VOR at both 0.5 and $5 \mathrm{~Hz}$. Second, for vestibular and climbing fiber pathways to use a single neural learning rule to guide motor learning across stimuli with a wide range of temporal dynamics (e.g., at both $0.5 \mathrm{~Hz}$ and $5 \mathrm{~Hz}$ ), a plasticity mechanism must be selectively driven by climbing fiber inputs that follow activity in a vestibular input by $\sim 100 \mathrm{msec}$ (i.e., climbing fiber activity that follows the vestibular input by $\sim 100 \mathrm{msec}$ must be more effective than simultaneous climbing fiber activity).

These properties do not match current knowledge of the timing contingencies for the best-studied form of plasticity in the cerebellum, LTD in the cerebellar cortex (cerebellar LTD; Ito et al. 1982;
Ekerot and Kano 1985, 1989; Sakurai 1987; Schreurs and Alkon 1993; Lev-Ram et al. 1995). Studies in brain slice and culture systems, as well as in vivo, suggest that LTD is most effectively induced when climbing fiber activity precedes or is simultaneous with parallel fiber activity. To the extent that climbing fiber stimulation that follows parallel fiber stimulation is effective in inducing plasticity, it has been reported to induce changes in the same direction as simultaneous climbing fiber and parallel fiber stimulation (Schreurs and Alkon 1996; Chen and Thompson 1995). If cerebellar LTD contributes to the induction of appropriate learned changes in the VOR under all conditions in which learning occurs, then future studies will have to explain how to resolve this discrepancy between the timing of the signals actually available to guide learning and the apparent lack of appropriate temporal properties in the cellular mechanisms of LTD. It is unlikely that delays in the vestibular pathways to the cerebellar cortex can resolve this timing problem, because these delays are estimated to be only $\sim 20 \mathrm{msec}$ (Lisberger et al. 1994c). Therefore the required comparison of neural signals across time would need to be largely a feature of the cellular processes at the site of plasticity. It may be that such a mechanism exists at the brain-stem site of plasticity, or it may be that the properties of cerebellar LTD that have been measured with available techniques do not accurately reflect the normal operation of this mechanism in vivo with natural activation of the input pathways.

As an alternative to requiring a cellular mechanism of plasticity tuned for noncoincident inputs, motor learning in the VOR may use multiple cellular mechanisms of plasticity. Several observations are consistent with this idea. First, previous studies have suggested the existence of two components of learning in the VOR that are differentially induced by high- and low-frequency stimuli and that have differential effects on the amplitude and dynamics of the VOR (Raymond and Lisberger 1996a). Second, we have shown here (Fig. 3) that different amounts of retinal image movement and eye movement signals, and therefore different potential error signals, are available at high versus low frequencies. Third, available data suggest that there are at least two sites of plasticity in the circuit for the VOR (Dufosse et al. 1978; Miles et al. 1980b; Watanabe 1984; Lisberger and Pavelko 1988; Lisberger 1994; Lisberger et al. 1994b,c; Luebke and Robinson 1994; Pastor et al. 1994; Partsalis et al. 1995), and it seems likely that different

$$
\text { n...... }
$$


anatomical sites would use different neural learning rules. Our data do not address the issue of where particular combinations of neural signals may act. In theory, the climbing fibers, vestibular inputs, and simple-spike activity each could act either in the cerebellar cortex or at the FTNs in the vestibular nucleus. Finally, it should be noted that our recordings reflect only the signals available at the beginning of learning. Once the first changes have been induced in the circuit for the VOR, additional mechanisms could be activated by the altered neural activity produced by the initial changes (see Raymond et al. 1996). Together, these results raise the possibility that cerebellumdependent motor learning uses a number of different cellular mechanisms of plasticity and error signals and, possibly, multiple sites of learning to ensure that the system works over the wide range of stimuli encountered in natural settings.

\section{Acknowledgments}

This work was supported by National Institutes of Health grant EY10198 (S.G.L.) and a National Aeronautics and Space Administration Research Associate Fellowship (J.L.R.)

The publication costs of this article were defrayed in part by payment of page charges. This article must therefore be hereby marked "advertisement" in accordance with 18 USC section 1734 solely to indicate this fact.

\section{References}

Albus, J.S. 1971. A theory of cerebellar function. Math. Biosci. 10: 25-61.

Balaban, C.D., Y. Kawaguchi, and E. Watanabe. 1981. Evidence of a collateralized climbing fiber projection from the inferior olive to the flocculus and vestibular nuclei in rabbits. Neurosci. Lett. 22: 23-29.

Barmack, N.H. and V.E. Pettorossi. 1985. Effects of unilateral lesions of the flocculus on optokinetic and vestibuloocular reflexes of the rabbit. J. Neurophysiol. 53: 481-496.

Buttner, U. and W. Waespe. 1984. Purkinje cell activity in the primate flocculus during optokinetic stimulation, smooth pursuit eye movements and VOR-suppression. Exp. Brain Res. 55: 97-104.

Chen, C. and R.F. Thompson. 1995. Temporal specificity of long-term depression in parallel fiber-Purkinje synapses in rat cerebellar slice. Learn. \& Mem. 2: 185-198.

Dufosse, M., M. Ito, P.J. Jastreboff, and Y. Miyashita. 1978. A neural correlate in rabbit's cerebellum to adaptive modification of the vestibulo-ocular reflex. Brain Res. 150: 611-616.
Ekerot, C.-F. and M. Kano. 1985. Long-term depression of parallel fibre synapses following stimulation of climbing fibres. Brain Res. 342: 357-360.

1989. Stimulation parameters influencing climbing fibre induced long-term depression of parallel fibre synapses. Neurosci. Res. 6: 264-268.

Gauthier, G.M. and D.A. Robinson. 1975. Adaptation of the human vestibulo-ocular reflex to magnifying lenses. Brain Res. 92: 331-335.

Gonshor, A. and G. Melvill Jones. 1973. Changes of human vestibulo-ocular response induced by vision-reversal during head rotation. J. Physiol. 234: 102-103P.

Graf, W., J.I. Simpson, and C.S. Leonard. 1988. Spatial organization of visual messages of the rabbit's cerebellar flocculus. II. Complex and simple spike responses of Purkinje cells. J. Neurophysiol. 60: 2091-2121.

Ito, M. 1972. Neural design of the cerebellar motor control system. Brain Res. 40: 81-84.

Ito, M. 1982. Cerebellar control of the vestibulo-ocular reflex-around the flocculus hypothesis. Annu. Rev.

Neurosci. 5: 275-298.

Ito, M., T. Shiida, N. Yagi, and M. Yamamoto. 1974. The cerebellar modification of rabbit's horizontal vestibulo-ocular reflex induced by sustained head rotation combined with visual stimulation. Proc. Jpn. Acad. 50: 85-89.

Ito, M., M. Sakurai, and P. Tongroach. 1982. Climbing fibre induced depression of both mossy fibre responsiveness and glutamate sensitivity of cerebellar Purkinje cells. J. Physiol. (Lond.) 324: 113-134.

Judge, S.J., B.J. Richmond, and F.C. Chu. 1980. Implantation of magnetic search coils for measurement of eye position: An improved method. Vision Res. 20: 535-538.

Langer, T., A.F. Fuchs, C.A. Scudder, and M.C. Chubb. 1985. Afferents to the flocculus of the cerebellum in the rhesus macaque as revealed by retrograde transport of horseradish peroxidase. J. Comp. Neurol. 235: 1-25.

Lev-Ram, V, L.R. Makings, P.F. Keitz, J.P.Y. Kao, and R.Y. Tsien. 1995. Long-term depression in cerebellar Purkinje neurons results from coincidence of nitric oxide and depolarization-induced $\mathrm{Ca}^{2+}$ transients. Neuron 15: 407-415.

Lisberger, S.G. 1994. Neural basis for motor learning in the vestibuloocular reflex of primates. III. Computational and behavioral analysis of the sites of learning. J. Neurophysiol. 72: 974-998.

Lisberger, S.G. and A.F. Fuchs. 1974. Response of flocculus Purkinje cells to adequate vestibular stimulation in the alert monkey: Fixation vs. compensatory eye movements. Brain Res. 69: 347-353.

1978. Role of primate flocculus during rapid behavioral modification of vestibuloocular reflex. I. Purkinje cell activity during visually guided horizontal smooth-pursuit eye movements and passive head rotation. J. Neurophysiol. 41: 733-763.

Lisberger, S.G. and L.E. Westbrook. 1985. Properties of visual inputs that initiate horizontal smooth pursuit eye movements in monkeys. J. Neurosci. 5: 1662-1673. 
Lisberger, S.G. and T.A. Pavelko. 1988. Brain stem neurons in modified pathways for motor learning in the primate vestibulo-ocular reflex. Science 242: 771-773.

Lisberger, S.G. and T.J. Sejnowski. 1992. Motor learning in a recurrent network model based on the vestibulo-ocular reflex. Nature 360: 159-161.

Lisberger, S.G., F.A. Miles, and D.S. Zee. 1984. Signals used to compute errors in monkey vestibulo-ocular reflex: Possible role of flocculus. J. Neurophysiol. 52: 1140-1153.

Lisberger, S.G., T.A. Pavelko, and D.M. Broussard. 1994a. Responses during eye movements of brain stem neurons that receive monosynaptic inhibition from the flocculus and ventral paraflocculus in monkeys. J. Neurophysiol. 72: 909-927.

1994b. Neural basis for motor learning in the vestibuloocular reflex of primates. I. Changes in the responses of brain stem neurons. J. Neurophysiol. 72: 928-953.

Lisberger, S.G., T.A. Pavelko, H.M. Bronte-Stewart, and L.S. Stone. 1994c. Neural basis for motor learning in the vestibuloocular reflex of primates. II. Changes in the responses of horizontal gaze velocity Purkinje cells in the cerebellar flocculus and ventral paraflocculus. J.

Neurophysiol. 72: 954-973.

Luebke, A.E. and D.A. Robinson. 1994. Gain changes of the cat's vestibulo-ocular reflex after flocculus deactivation. Exp. Brain Res. 98: $379-390$.

Marr, D. 1969. A theory of cerebellar cortex. J. Physiol. 202: $437-470$.

Miles, F.A. and J.H. Fuller. 1974. Adaptive plasticity in the vestibulo-ocular responses of the rhesus monkey. Brain Res. 80: $512-516$.

1975. Visual tracking and the primate flocculus. Science 189: 1000-1002.

Miles, F.A. and S.G. Lisberger. 1981. Plasticity in the vestibulo-ocular reflex: A new hypothesis. Annu. Rev. Neurosci. 4: 273-299.

Miles, F.A., J.H. Fuller, D.J. Braitman, and B.M. Dow. 1980a. Long-term adaptive changes in primate vestibuloocular reflex. III. Electrophysiological observations in flocculus of normal monkeys. J. Neurophysiol. 43: 1437-1476.

Miles, F.A., D.J. Braitman, and B.M. Dow. 1980b. Long-term adaptive changes in primate vestibuloocular reflex. IV. Electrophysiological observations in flocculus of adapted monkeys. J. Neurophysiol. 43: 1477-1493.

Nagao, S. 1983. Effects of vestibulocerebellar lesions upon dynamic characteristics and adaptation of vestibulo-ocular and optokinetic responses in pigmented rabbits. Exp. Brain Res. 53: 152-168.

1992. Different roles of flocculus and vental paraflocculus for oculomotor control in the primate. NeuroReport 3: 13-16.
Noda, H. and D.A. Suzuki. 1979. Processing of eye movement signals in the flocculus of the monkey. J. Physiol. 294: 349-364.

Partsalis, A.M., Y. Zhang, S.M. Highstein. 1995. Dorsal Y group in the squirrel monkey. II. Contribution of the cerebellar flocculus to neuronal responses in normal and adapted animals. J. Neurophysiol. 73: 632-649.

Pastor, A.M., R.R. de la Cruz, and R. Baker. 1994. Cerebellar role in adaptation of goldfish vestibuloocular reflex. $J$. Neurophysiol. 72: 1383-1394.

Precht, W. and R. Llinas. 1969. Functional organization of the vestibular afferents to the cerebellar cortex of frog and cat. Exp. Brain Res. 9: 30-52.

Raymond, J.L. and S.G. Lisberger. 1996a. Behavioral analysis of signals that guide learned changes in the amplitude and dynamics of the vestibulo-ocular reflex. J. Neurosci. 16: $7791-7802$.

1996b. Error signals in horizontal gaze velocity Purkinje cells under stimulus conditions that cause learning in the VOR. Ann. N.Y. Acad. Sci. 781: 686-689.

Raymond, J.L., S.G. Lisberger, and M.D. Mauk. 1996. The cerebellum: A neuronal learning machine? Science 272: $1126-1131$.

Robinson, D.A. 1976. Adaptive gain control of the vestibulo-ocular reflex by the cerebellum. J. Neurophysiol. 39: 954-969.

Sakurai, M. 1987. Synaptic modification of parallel fibre-Purkinje cell transmission in in vitro guinea-pig cerebellar slices. J. Physiol. (Lond.) 394: 463-480.

Schreurs, B.G. and D.L. Alkon. 1993. Rabbit cerebellar slice analysis of long-term depression and its role in classical conditioning. Brain Res. 631: 235-240.

1996. Pairing-specific long-term depression of Purkinje cell excitatory postsynaptic potentials results from a classical conditioning procedure in the rabbit cerebellar slice. J. Neurophysiol. 75: 1051-1060.

Stone, L.S. and S.G. Lisberger. 1990. Visual responses of Purkinje cells in the cerebellar flocculus during smooth pursuit eye movements in monkeys. I. Simple spikes. J. Neurophysiol. 63: 1241-1261.

Waespe, W. and V. Henn. 1981. Visual-vestibular interaction in the flocculus of the alert monkey. II. Purkinje cell activity. Exp. Brain Res. 43: 349-360.

Watanabe, E. 1984. Neuronal events correlated with long-term adaptation of the horizontal vestibulo-ocular reflex in the primate flocculus. Brain Res. 297: 169-174.

Wurtz, R.H. 1969. Visual receptive fields of striate cortex neurons in awake monkeys. Neurosci. Res. 32: 727-742.

Received February 18, 1997; accepted in revised form April 14, 1997.

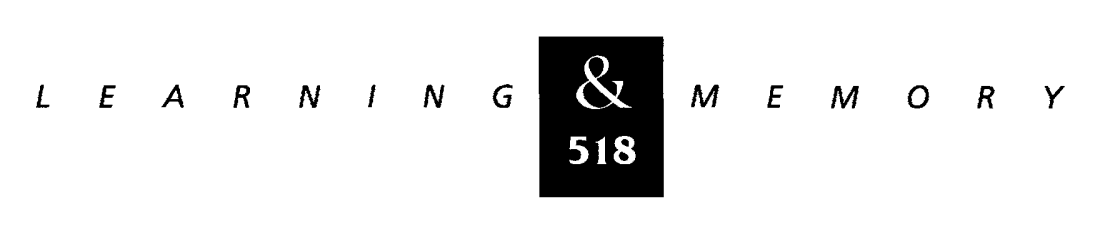




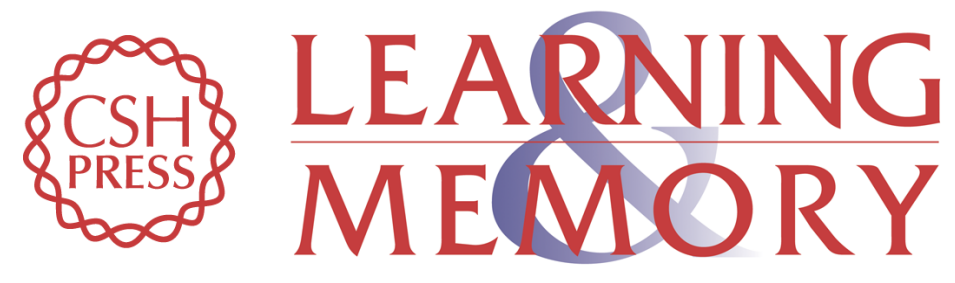

\section{Multiple subclasses of purkinje cells in the primate floccular complex provide similar signals to guide learning in the vestibulo-ocular reflex.}

J L Raymond and S G Lisberger

Learn. Mem. 1997, 3:

Access the most recent version at doi:10.1101//m.3.6.503

References This article cites 52 articles, 6 of which can be accessed free at: http://learnmem.cshlp.org/content/3/6/503.full.html\#ref-list-1

License

Email Alerting

Receive free email alerts when new articles cite this article - sign up in the box at the Service top right corner of the article or click here. 